\title{
Spontaneous Coronary Dissection with Dissection of Ascending Aorta and Cardiac Tamponade
}

\section{Ivan Stojanovic ${ }^{1 *}$, Goran Ilic ${ }^{2}$, Maja Stojanovic ${ }^{3}$ and Ivan Ilic ${ }^{4}$}

${ }^{1}$ Institute of Forensic Medicine, Faculty of Medicine, University of Nis, Serbia

${ }^{2}$ Professor, Institute of Forensic Medicine, Faculty of Medicine, University of Nis, Serbia

${ }^{3}$ Institute for Health Protection of Railway workers in Nis, Serbia

${ }^{4}$ Institute of Pathology, Faculty of Medicine, University of Nis, Serbia

\begin{abstract}
Spontaneous Coronary Artery Dissection (SCAD) is a rare but potentially lethal event. A 46-year-old woman presented to her local hospital at 11:30 pm with an abrupt onset of severe chest pain, which occur one hour before. Diagnosis of acute myocardial infarction non-STEMI was set. The autopsy as a direct cause of death revealed cardiac tamponade from a ruptured dissection of ascending aorta that start with a rupture of right coronary artery. Microscopic examination of coronary artery revealed that a rupture occurred on junction between normal and abnormal intima and thin subintimal-media layer, because of loose of collagen fibers. Our case confirmed association of primary coronary artery dissections with female sex. As a direct cause of primary coronary artery dissection we identified loose of collagen fibers in intimal and subintimal-media layer.
\end{abstract}

Keywords: Coronary artery dissection; Dissecting aortic aneurysm; Cardiac tamponade; Acute myocardial infarction

\section{Introduction}

Spontaneous Coronary Artery Dissection (SCAD) is a rare but potentially lethal event. The cause of spontaneous coronary dissection is poorly understood. There are reported associations with female sex, exercise, pregnancy and postpartum state, coronary artery disease, connective tissue disorders and hemorrhage into the vasovasorum and periadventitial inflammation [1-7]. Most cases have no identifiable risk factor [1,7]. In patients presenting with acute coronary syndrome and cardiac tamponade, acute Spontaneous Coronary Artery Rupture (SCAD) is a possible diagnosis [8,9]. Patients may present with a broad spectrum of clinical scenarios, ranging from angina pectoris to myocardial infarction, cardiogenic shock, and sudden death [9-12]. In literature, only few cases of spontaneous coronary artery dissection causing cardiac tamponade were described [8,13-15].

As a very unusual complication of coronary intervention was simultaneous aortocoronary dissection with or without pericardial tamponade [16-19]. Some authors are making difference between spontaneous coronary artery dissection (SCAD) and rupture (SCAR) and suggest that SCAD is more common than SCAR as reported in the literature [14]. Most of authors suggest that this is same event [6].

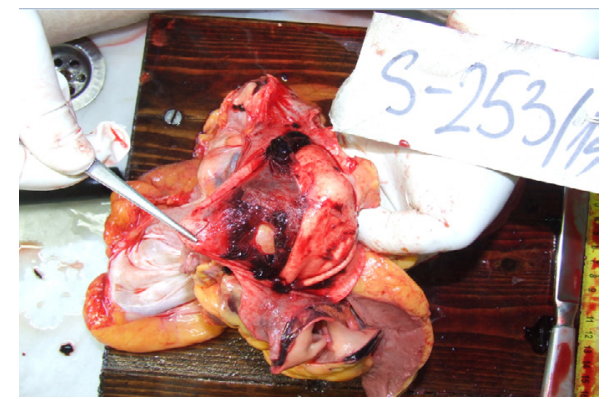

Figure 1: A ruptured dissection of ascending aorta.

\section{Case Report}

\section{History}

A 46-year-old woman presented to her local hospital at 11:30 pm with an abrupt onset of severe chest pain, which occur one hour before. She was a smoker and had been not well treated for hypertension. She had a hysterectomia with both side adnexectomia, long time before. Clinical examination revealed pulse rate $69 / \mathrm{min}$ and blood pressure $170 / 100 \mathrm{mmHg}$. The electrocardiogram showed $\mathrm{T}$ wave inversion in D1, D3, V4, V5 and V6, with axis shift to the left. Echocardiography, both transthoracic and transesophageal, was not performed not even was planed. Diagnosis of acute myocardial infarction non-STEMI was set. During diagnostics procedures, nausea and the urge to vomit occur. She was given glucose solution $250 \mathrm{ml}$, gliceriltrinitrat, cardiopirin, ramipril, metamizole and ranitidine.

In medical records, there were no data about next 6 hours (from 00 to $06 \mathrm{am})$. Death pronounced at $06 \mathrm{am}$.

\section{Autopsy}

The autopsy was performed in Institute of Forensic Medicine in Nis, and as a direct cause of death revealed cardiac tamponade from a ruptured dissection of ascending aorta (Figure 1). Detailed examination of coronary arteries revealed that a dissection of ascending aorta start with a rupture of right coronary artery. A rupture of right coronary artery founded on its upper wall and $3 \mathrm{~mm}$ downstream from aorta, that was $3 \mathrm{~mm}$ long (Figure 2). A coronary arteries presented minimal

*Corresponding author: Stojanovic I, Institute of Forensic Medicine, Faculty of Medicine, University of Nis, Serbia, Tel: +381-63-8141172; E-mail: stojanovic81@yahoo.com

Received November 06, 2014; Accepted November 25, 2014; Published November 27, 2014

Citation: Stojanovic I, llic G, Stojanovic M, llic I (2014) Spontaneous Coronary Dissection with Dissection of Ascending Aorta and Cardiac Tamponade. J Vasc Med Surg 2: 165. doi: 10.4172/2329-6925.1000165

Copyright: (c) 2014 Stojanovic I, et al. This is an open-access article distributed under the terms of the Creative Commons Attribution License, which permits unrestricted use, distribution, and reproduction in any medium, provided the original author and source are credited. 


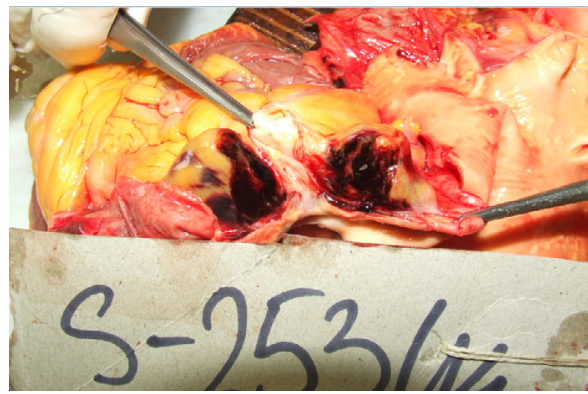

Figure 2: A rupture of right coronary artery.

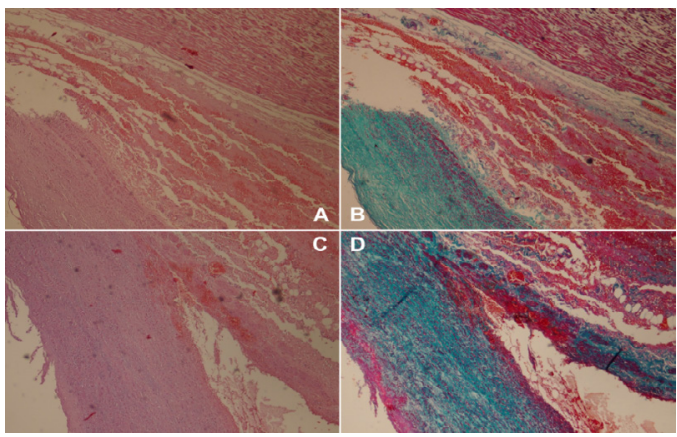

Figure 3: A hemorrhage under the rupture of coronary artery ( $A$ and $B)$ and a longitudinal dissection of tunica media of ascending aorta (Cand D), (microscopic view x40, HE and Masson's trichrome)

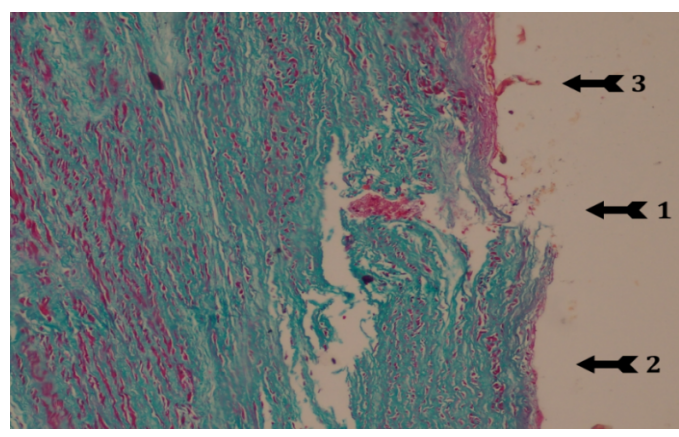

Figure 4: microscopic view $\times 100$, Masson's trichrome (1 - the rupture of coronary artery; 2 -normal intima and subintima of coronary artery, downstream of rupture; 3 - abnormal intima and subintima of coronary artery, upstream of rupture, because of loose of collagen).

atherosclerotic disease. The autopsy also revealed that a heart was slight hypertrophic with fatty permeation of right ventricle, severe fatty permeation of liver and chronic pyelonephritis.

Microscopic findings: Pathohistology examination confirmed macroscopic observations (Figure 3). Microscopic examination of coronary artery also revealed that a rupture occurred on junction between normal and abnormal intima and thin subintimal-media layer (Figure 4). Abnormal intima and subintimal-media layer are presented as a red colored zone (Masson's trichrome stain), because of loose of collagen fibers.

Toxicology findings: Toxicology was negative.

\section{Discussion}

Even though few reports of cases like this exist, we believe the disease might be underreported because an acute bleeding in the pericardium is often lethal and thus not recognized by doctors, as a literature suggests [13]. Primary coronary artery dissections, as in our case, are much less common than secondary dissections, and their etiology remains unclear. Associations of primary coronary artery dissections with female sex, exercise, pregnancy and postpartum state, coronary artery disease, connective tissue disorders and hemorrhage into the vasovasorum and periadventitial inflammation, have been noted [1-7]. Our case confirmed association of primary coronary artery dissections with female sex. As a direct cause of primary coronary artery dissection we identified loose of collagen fibers in intimal and subintimal-media layer with high blood pressure $(170 / 100 \mathrm{mmHg}$ on arrival in hospital). A connection between hormonal disturbances in women and connective tissue disorders, also as collagen, is well known. In our case, relationship between hormonal disturbances and connective tissue disorders (loose of collagen fibers in aorta) could be assigned to hysterectomia with both side adnexectomia, but this could not be confirmed. Myocardial infarction secondary to primary coronary artery dissection is exceedingly rare. While coronary artery dissection may present as acute myocardial infarction or as sudden death, sudden death accounts for the majority of presentations, thus leading to diagnosis usually at autopsy. In our case, presentation of acute myocardial infarction misleads doctors and precious time was wasted. If a dissection of coronary artery and aorta was recognized shortly after arrival in hospital, urgent thoracic surgery might save life of this woman.

\section{Summary}

In summary, we presented a case of a 46-year-old woman with acute myocardial infarction secondary to a right coronary artery dissection with propagation into dissection of ascending aorta and cardiac tamponade. This case should hold doctors caution when approaching a patient with acute myocardial infarction. Also, Masson's trichrome stain, as a very cheap histology stain technique, give as very important information that a primary coronary artery dissection could be connected with a collagen disturbances. Cases like this are extremely rare and presentation of our case should improve forensic medicine in understanding sudden death.

Because of technical and financial difficulties we could not perform other diagnostic procedures (immunohistochemistry, DNA analysis etc.), that could be very helpful to indentify cause of coronary artery dissection. We are going to be honored to help further research and provide our material to scientists in this field.

\section{References}

1. Thompson EA, Ferraris S, Gress T, Ferraris V (2005) Gender differences and predictors of mortality in spontaneous coronary artery dissection: a review of reported cases. J Invasive Cardiol 17: 59-61.

2. Sibon I, Sommer P, Lamaziere JM, Bonnet J (2005) Lysyl oxidase deficiency: a new cause of human arterial dissection. Heart 91: e33.

3. Ishii T, Asuwa N (2000) Collagen and elastin degradation by matrix metalloproteinases and tissue inhibitors of matrix metalloproteinase in aortic dissection. Hum Pathol 31: 640-646.

4. Germain DP, Herrera-Guzman Y (2004) Vascular Ehlers-Danlos syndrome. Ann Genet 47: 1-9.

5. Lesauskaite V, Tanganelli P, Sassi C, Neri E, Diciolla F, et al. (2001) Smooth muscle cells of the media in the dilatative pathology of ascending thoracic aorta: morphology, immunoreactivity for osteopontin, matrix metalloproteinases, and their inhibitors. Human pathology 32: 1003-1011. 
Citation: Stojanovic I, llic G, Stojanovic M, llic I (2014) Spontaneous Coronary Dissection with Dissection of Ascending Aorta and Cardiac Tamponade. J Vasc Med Surg 2: 165. doi: 10.4172/2329-6925.1000165

6. Fontanellia A, Olivarib Z, La Vecchiaa L, Bassoc C, Pagliania L, et al. (2009) Spontaneous dissections of coronary arteries and acute coronary syndromes: rationale and design of the DISCOVERY, a multicenter prospective registry with a case-control group. Journal of Cardiovascular Medicine 10: 94-99.

7. Maeder M, Ammann P, Angehrn W, Rickli H (2005) Idiopathic spontaneous coronary artery dissection: incidence, diagnosis and treatment. Int $\mathrm{J}$ Cardiol 101: 363-369.

8. Butz T, Lamp B, Figura T, Faber L, Esdorn H, et al. (2007) Images in cardiovascular medicine. Pericardial effusion with beginning cardiac tamponade caused by a spontaneous coronary artery rupture. Circulation 116: e383-384.

9. Almeda FQ, Barkatullah S, Kavinsky CJ (2004) Spontaneous coronary artery dissection. Clin Cardiol 27: 377-380.

10. Pothiawala S, Lateef $F(2013)$ A case of spontaneous coronary artery dissection: it is not always plaque rupture. J Emerg Med 44: 92-95.

11. Dhawan R, Singh G, Fesniak $H$ (2002) Spontaneous coronary artery dissection: the clinical spectrum. Angiology 53: 89-93.

12. Farsak B, Oc M, Oc B, Simsek M, Akbayrak H, et al. (2012) Spontaneous coronary artery dissections: three case reports and review of literature. Heart Surg Forum 15: E232-235.

13. Kaljusto ML, Koldsland S, Vengen OA, Woldbaek PR, Tønnessen T (2006) Cardiac tamponade caused by acute spontaneous coronary artery rupture. J Card Surg 21: 301-303
14. Shrestha BM, Hamilton-Craig C, Platts D, Clarke A (2009) Spontaneous coronary artery rupture in a young patient: a rare diagnosis for cardiac tamponade. Interact Cardiovasc Thorac Surg 9: 537-539.

15. Hayes CR, Lewis D (2007) Spontaneous coronary artery dissection of the left circumflex artery causing cardiac tamponade and presenting with atrial fibrillation: a case report and review of the literature. Angiology 58: 630-635.

16. Portoa I, Mitchella ARJ, Selvanayagamb JB, Neubauerb S, Banninga AP (2005) Percutaneous treatment of simultaneous aortic dissection and pericardial tamponade during coronary intervention. International Journal of Cardiology 105: 104-107.

17. Dunning DW, Kahn JK, Hawkins ET, O'Neill WW (2000) latrogenic coronary artery dissections extending into and involving the aortic root. Catheter Cardiovasc Interv 51: 387-393.

18. Dahdouh Z, Roule V, Lognoné T, Sabatier R, Bignon M, et al. (2012) latrogenic bidirectional dissection of the right coronary artery and the ascending aorta: the worst nightmare for an interventional cardiologist. Korean Circulation Journal.

19. Cheng CC, Tsao TP, Tzeng BH, Cheng SM, Yang SP (2008) Stenting for coronary intervention-related dissection of the left main coronary artery with extension to the aortic root: a case report. South Med J 101: 1165-1167. 